\title{
DESAIN SARANA BAWA PEKERJA BANGUNAN UNTUK AKTIVITAS KETINGGIAN DI SAMARINDA
}

\author{
Royke Vincentius $\mathbf{F}^{\mathbf{1}}$ \\ ${ }^{1}$ Staf Pengajar Program Studi Desain Produk, Jurusan Desain \\ Politeknik Negeri Samarinda \\ Alfianor ${ }^{2}$ \\ ${ }^{2}$ Mahasiswa Program Studi Desain Produk, Jurusan Desain \\ Politeknik Negeri Sanarinda
}

\begin{abstract}
ABSTRAK
Bangunan meliputi rumah, gedung, ataupun segala sarana dan prasarana tempat tinggal yang dibutuhkan dalam kehidupan manusia. Dalam melakukan kegiatan pembangunan dibutuhkanlah alat-alat bangunan, dari alat yang berat sampai dengan alat yang sederhana. Sebagai pekerjaan khusus pada suatu proses pembangunan di butuhkan semua peralatan tersebut dalam aktivitas pertukangan termasuk pada kondisi ketinggian yang sulit dan berbahaya bagi para pekerja bangunan. Maka diperlukan bagaimana cara membawa semua alat perkakas bangunan itu dengan aman.

Melalui proses desain yakni dimulai dengan pengumpulan data, pengamatan, menganalisis yang menghasilkan spesifikasi desain dan membuat alternative desaian serta menentukan desaian akhir sebagai final desain.

Maka dihasilkan suatu perancangan sarana bawa yang dapat menaggulangi kelalaian pada saat membawa alat perkakas bangunan. Sarana bawa tersebut harus aman dan fungsional saat di gunakan. Perancangan desaian sarana bawa menghasilkan sebuah rompi yang memiliki kantong khusus yaitu alat bangunan beserta dengan alat safety berupa full body harness keselamatan saat berada di aktivitas ketinggian.
\end{abstract}

Kata kunci: rompi perkerja bangunan, aktivitas ketinggian, keselamatan, peralatan,

\begin{abstract}
Buildings also commonly called home, building, or any other facilities and infrastructure needed as a place to stay in human life. In conducting construction activities needs building tools, from heavy to simple tools. and is used as a special job in a construction process needs all the tools in all builder activities, including at altitude and dangerous conditions for builders. Then how to carry all that construction tools safely?. Through the design process, starts with data collection, observation, analyzing which generate a design specification and create alternative design and to determine final design. Then required a design of carrying facilities that can provide security when carrying construction tools. That carrying facilities must be safe and functional when used. This carrying facilities design produce a vest that has specific pockets which is construction tools as well as safety tools such as full body harness safety while in height activities.
\end{abstract}

Keywords: "design, construction workers take the means, of altitude, Safety, tools" 
Vol. 2, No. 2, April 2015

\section{Pendahuluan}

Bangunan adalah suatu hasil kebudayaan manusia. Bangunan biasa juga disebut dengan rumah, gedung, termasuk didalamnya segala sarana, prasarana atau infrastruktur. Dalam melakukan kegiatan dibutuhkan alat-alat bangunan, dari alat yang berat sampai dengan alat yang sederhana. Pada suatu proses pengerjaan bangunan saat berada di kondisi ketinggian maka situasi menjadi sulit untuk melakukan pekerjaan bangunan dan cenderung berbahaya. Bagi para pekerja bangunan tidak boleh terjadi kelalaian, meskipun kesalahannya sederhana. Selain berbahaya bagi diri sendiri, kelalaian dalam pekerja dapat membahayakan pekerja bangunan lainnya yang sedang berkatifitas. Kelalaian seperti tertimpa perkakas saat berada di ketinggian dapat membuat pekerja lain terluka dan dapat berakibat fatal bagi pekerja.

Peralatan tangan atau handtool pekerja bangunan di butuhkan pada suatu proses pembuatan gedung. Membawa handtool tentunya sangat susah dalam jumlah dan jenis yang banyak serta berbahaya pada bangunan yang bertingkattingkat.. Oleh karena itu di butuhkanlah sarana bawa agar mempermudah membawa peralatan tukang saat melakukan pekerjaan di ketinggian untuk mehindari terjadinya kelalaian, seperti kejatuhan palu, terinjak oleh paku, dan dapat tertimpa alat bangunan. Alat sarana bawa yang sudah ada saat ini hanya berupa box penyimpan alat, dan masih di butuhkan inovasi khusus untuk pekerja yang melakukan pekerjaan di ketinggian.
Dalam perundang undangan K3

Permenakertrans RI No 1 tahun 1980 menyatakan bahwa dengan semakin meningkatnya pembangunan dengan penggunaan teknologi modern, harus diimbangi pula dengan upaya keselamatan tenaga kerja atau orang lain yang berada di tempat kerja, terjadi kecelakaan, akibat belum ditanganinya pengawasan keselamatan dan kesehatan kerja secara mantap dan menyeluruh pada pekerjaan konstruksi bangunan, sehingga karenanya perlu diadakan upaya untuk membina norma perlindungan kerjanya.

Pada perusahaan konstruksi penting bagi perusahaan mempriotaskan keselamatan kerja dan menciptakan lingkukangan kerja yang kondusif guna menjaga keselamatan seluruh pekerja perusahaan. Pihak konstruksi wajib memastikan bahwa seluruh karyawan menjalankan tugasnya sesuai dengan prosedur standar keselamatan yang sesuai dengan peraturan perusahaan pada K3.

Dalam wawancara yang dilakukan penulis pada salah satu perumusan/situs konstruksi bangunan ternyata banyak kasus kecelakan kerja yang dikarenakan kelalaian menggunakan handtool. Contohnya kejatuhan barang seperti palu, tang, bor; juga terdapat beberapa kasus pekerja bangunan yang terinjak oleh paku. Tindakan preventif yang dilakukan konstruksi bangunan agar menghindari kecelakan saat kerja yaitu Induksi safety sesuai pada Undang-undang K3, yaitu pemakaian APD (alat pelindung 
Royke Vincentius F, Alfianor, Desain Sarana Bawa Pekerja Bangunan Untuk Aktivitas Ketinggian Di Samarinda

diri) yaitu seperti helm, rompi, dan sepatu boots APK (Alat Pengaman Kerja). Akan tetapi sesuai dengan ketentuan pasal $12 \mathrm{~K} 3$ tersebut, pada peratutan perusahaan harus terus melakukan penyesuaian dan perbaikan yang terus menerus terhadap perkembangan teknologi keselamatan kerja.

Menurut data ILO (International Labour Organization) diperkirakan sekitar 337 juta kecelakaan kerja terjadi tiap tahunnya yang mengakibatkan sekitar 2,3 juta pekerja kehilangan nyawa. Hal ini juga diamini oleh PT. Jamsostek bahwa sekitar 0.7 persen pekerja Indonesia mengalami kecelakaan yang mengakibatkan kerugian negara yang cukup banyak yakni mencapai 50 triliyun (Lingga, 2011).

Dalam suatu data kuisioner yang di bagikan kepada perkerja bangunan mengenai kelalaian pekerja bangunan, ternyata 7 dari 10 pekerja bangunan pernah menjatuhkan alat bangunan dengan sengaja atau tidak sengaja ke bawah bangunan.hal sederhana tersebut terbukti dapat membahayakan pekerja bangunan lainnya. Hasil kuisioner juga mengungkapkan bahwa para pekerja bangunan merasa membutuhkan sarana bawa yang lebih aman lagi dalam membawa peralatan untuk bekerja dalam kondisi di ketinggian.

\section{Metode Penelitian}

Dalam peneltian ini dilakukan dalam beberapa tahap tahap yaitu:

\section{Elementary desain}

Berupa pengumpulan data dan informasi, analisis data berdasarkan konsep desain makro yang meliputi analisis (konsep fungsi, konsep pemakai, konsep pasar, dan konsep produk), penyusunan program desain dan sketsa awal. Dalam tahap ini dilakukan uga studi pustaka sebagi rujukan, analisis data yang akn diperguanakn, wawancara dengan arasumbwer, perumusan masalah, yang akhirnya merumuskan spesifikasi desain. .

\section{Design Development}

Pada tahap ini dibuat alternatif gambar komponen serta rancangansecara wire diagram dengan bentuk 3D (tiga dimensi). Dari bagan yang tertera di atas terdiri dari beberapa alternative desain. Dari beberapa alternatif dipilih satu alternatif terpilih, selanjutnya dikemabngkan menjadi beberapa alternatif lagi, sehingga muncul desain final. 


\section{Final design \& Prototyping}

Dari desain final, dijabarkanb menjadi gambar kwerja yang nantinya bbisa diproduksi. Gambar tesebut meliputi gambar presentasi, gamnar isometri, gambar tampak, gambar potongan, gambar detail, dan gambar urai. Untuk pengoperaiasn dibuatkan animasi). Tahapan selanjutnya adalah pembuatan komponen-komponen dilakukan assembling (exploded) atau perakitan sehingga menjadi produk (prototype),

\section{Pembahasan}

Data Analisis aktivitas dan kebutuhan dilakukan untuk mengetahui aktivitas yang dilakukan berkaitan dengan produk yang akan dibuat sehingga diperoleh kebutuhan pengguna. Berdasarkan kebutuhan tersebut maka dibuat pemecahan untuk memenuhi kebutuhan yang dapat diaplikasikan pada produk. Adapun aktivitas yang dilakukan oleh pekerja bangunan dapat dilihat pada tabel 1 di bawah:

Tabel 2 memuat analisis aktivitas dan kebutuhan yang berkaitan dengan produk “ Desain Sarana Bawa Alat Pekerja Bangunan Untuk Aktifitas di Ketinggian”, yaitu:

Tabel 1 Aktivitas dan kebutuhan saat mulai beraktivitas sampai selesai beraktivitas

\begin{tabular}{|l|l|l}
\hline No. & \multicolumn{1}{|c|}{ Aktifitas } & \multicolumn{1}{c}{ Kebutuhan } \\
\hline 1. & Mengikat sarana bawa pada tubuh & Kuncian/ikatan Side relase buckle \\
\hline 2. & Meletakkan Alat Bangunan & Tempat khusus alat bangunan \\
\hline 3. & Membawa peralatan bangunan & Sarana Bawa Alat Bangunan \\
\hline 4. & Menuju tempat ketinggian & Tangga atau tiang bangunan \\
\hline 5. & $\begin{array}{l}\text { Mengunci belt kepada tiang bangunan } \\
\text { yang ada }\end{array}$ & Snap Hook \\
\hline 6. & $\begin{array}{l}\text { Mengambil alat bangunan pada wadah } \\
\text { sarana bawa }\end{array}$ & Alat dan wadah sarana bawa \\
\hline 7. & Menggunakan alat bangunan & $\begin{array}{l}\text { Gergaji,Palu,Tang,Paku,Meteran,Penggar } \\
\text { is, Pensil, Obeng }\end{array}$ \\
\hline 8. & $\begin{array}{l}\text { Mengembalikan alat bangunan pada } \\
\text { wadah sarana bawa }\end{array}$ & Alat dan wadah sarana bawa \\
\hline 9. & Turun kembali menuju lantai bawah & Tangga atau tiang bangunan \\
\hline
\end{tabular}


Royke Vincentius F, Alfianor, Desain Sarana Bawa Pekerja Bangunan Untuk Aktivitas Ketinggian Di Samarinda

Tabel 2 Kebutuhan alat perkakas

\begin{tabular}{|l|l|l|}
\hline No. & Alat Yang Dibutuhkan & \multicolumn{1}{c|}{ Kegunaan } \\
\hline 1. & Palu & Untuk menyambungkan paku \\
\hline 2. & Tang & $\begin{array}{l}\text { Mengencangkan Baut, membengkongkan kawat dan } \\
\text { besi }\end{array}$ \\
\hline 3. & Meteran & Untuk mengukur suatu bidang yang ditentukan \\
\hline 4. & Paku & Untuk menyambungkan kayu ataupun beton \\
\hline 5. & pahat & Untuk memahat kayu \\
\hline 6. & Pensil & $\begin{array}{l}\text { Untuk memberi tanda pada kerjaan yang sudah di } \\
\text { ukur }\end{array}$ \\
\hline 7 & Penggaris & $\begin{array}{l}\text { Untuk menghitung dan menggariskan tanda agar } \\
\text { lurus }\end{array}$ \\
\hline
\end{tabular}

Tabel 3 memuat Studi aktivitas dan kebutuhan pada saat bekerja di kondisi ketinggan mengguanakan alat sarana bawa alat bangunan.

Tabel 3 Aktivitas dan kebutuhan saat proses pertukangan

\begin{tabular}{|l|l|l|}
\hline No. & \multicolumn{1}{|c|}{ Aktifitas } & \multicolumn{1}{|c|}{ Kebutuhan } \\
\hline 1. & Mengaitkan Belt pada tiang & Snap hook untuk mengait \\
\hline 2. & Mengambil alat bangunan & $\begin{array}{l}\text { Tenpat khusus penyimpanan alat saat di } \\
\text { ketinggian }\end{array}$ \\
\hline 3. & Menggunakan palu & $\begin{array}{l}\text { Mengambil dan memukul paku pada kayu } \\
\text { ataupun beton }\end{array}$ \\
\hline 4. & Menggunakan paku & Untuk menguhubungkan anatara kayu dan kayu \\
\hline & Menggunakan gergaji & untuk memotong kayu \\
\hline 5. & Menggunakan Penggaris & Untuk menggaris atau memberi tanda \\
\hline 6. & Menggunakan tang & Untuk membengkokkan kawat \\
\hline 7. & Menggunakan pensil & Untuk memberi tanda pengukur \\
\hline 8. & Menggunakan obeng & Untuk memutar baut \\
\hline 9. & Menggunakan pahat & Untuk memahat kayu \\
\hline 10. & Menggunakan meteran & Untuk mengukur lokasi bangunan \\
\hline 11. & Mengembalikan alat bangunan & Menaruh kembali alat pada tempat sarana bawa \\
\hline
\end{tabular}

Berdasarkan analisis aktivitas dan kebutuhan yang terdapat pada tabel di atas, maka telah didapatkan kesimpulan mengenai komponen-komponen apa saja yang harus ada dalam produk, yaitu: (1) Memiliki tempat khusus peralatan tukang yang akan di bawa. (2) Memiliki kantung-kantung yang di pakai sebagai wadah alat bangunan. (3) Memiliki Belt pengaman pekerja bangunan agar tidak terjatuh. (4) Signal Safety sebagai peringatan bahwa ada seseorang di lokasi. (5) Terdapat tempat tersembunyi mengaitkan hook ke dalam ikan dada.

Data ergonomi dilakukan untuk meminimalkan resiko kecelakaan dan keselamatan dalam peroduk yang di rancang. Dengan begitu efisiensi kesehatan, keselamatan, dan kenyamanan dalam melakukan kegiatan menggunakan produk dapat maksimal. Sedangkan data 
Vol. 2, No. 2, April 2015

anthropometri dilakukan guna mendapatkan dimensi atau ukuran produk yang sesuai dengan tubuh pengguan. Berikut ini adalah titik ke ergonomisan pada produk yaitu: (1) Untuk kenyamanan sarana bawa saat digunakan adalah terletak pada lingkaran pinggang seberapa panjang pinggang yang harus sesuai dengan standar dengan lebar pinggang laki-laki dewasa. (2) Massa berat alat-alat yang di butuhkan yaitu gergaji, palu, obeng, tang, paku, penggaris, pensil, meteran, dan kapih, harus distribusi dengan baik keseluruh tubuh agar tidak berat sebelah. (3) Ke ergonomisan jangkauan tangan terhadap tempat-tempat penyimpanan alat pada sarana bawa yaitu seberapa luas jangkauan tangan pada tubuh manusia pada ukuran laki-laki dewasa. (4) Ke ergonomisan mengambil alat-alat bangunan di lakukan dengan cara mengukur seberapa lebar telapak tangan dan ukuran panjang jari beserta lebar kantung-kantung sesuai dengan lebar telapak tangan.

Berikut penjelasan yang lebih terperinci mengenai antropometri yang digunakan pada produk:

1. Antropometri yang digunakan untuk menentukan panjang rompi adalah dimensi antropometri tebal Dada dan Lebar Dada. Jenis antropometri yang digunakan untuk kelompok pria 50\% persentil, yaitu tebal dada $250 \mathrm{~mm}$ ditambah tinggi pinggul ke bahu $605 \mathrm{~mm}$ sama dengan $555 \mathrm{~mm}$. Perlu adanya pengurangan $50 \mathrm{~mm}$ untuk toleransi ikat Pinggang, 100 mm untuk kelonggaran pada Pinggang.

2. Panjang rompi $=$ tebal dada + tinggi pinggul ke bahu + toleransi $=250+$ $605+50=905 \mathrm{~mm}$

3. Anthropometri yang digunakan untuk menentukan Lebar Rompi adalah dimensi anthropometri Lebar Pinggang yaitu $314.10 \mathrm{~mm}$ dan lebar punggung $361.9 \mathrm{~mm}$. Lebar Rompi pekerja bangunan di ukurkan pada ukuran laki-laki dewasa.

4. Anthropometri yang digunakan untuk menentukan Lingkar leher Rompi adalah dimensi anthropometri Lebar Lingkaran Leher Rompi $70 \mathrm{~mm}$ Lebar LeherRompi pekerja bangunan di ukurkan pada ukuran laki-laki dewasa.

5. Anthropometri yang digunakan untuk menentukan lngkar tangan adalah dimensi anthropometri lingkar bahu 132.70 mm lingkar leher rompi pekerja bangunan di ukurkan pada ukuran laki-laki dewasa.

Analisis konfigurasi dilakukan guna mendapatkan susunan dari tiap-tiap komponen yang terdapat pada Sarana Bawa alat pekerja bangunan di aktivitas ketinggian. Adapun komponen yang terdapat pada produk adalah: 
Royke Vincentius F, Alfianor, Desain Sarana Bawa Pekerja Bangunan Untuk Aktivitas Ketinggian Di Samarinda

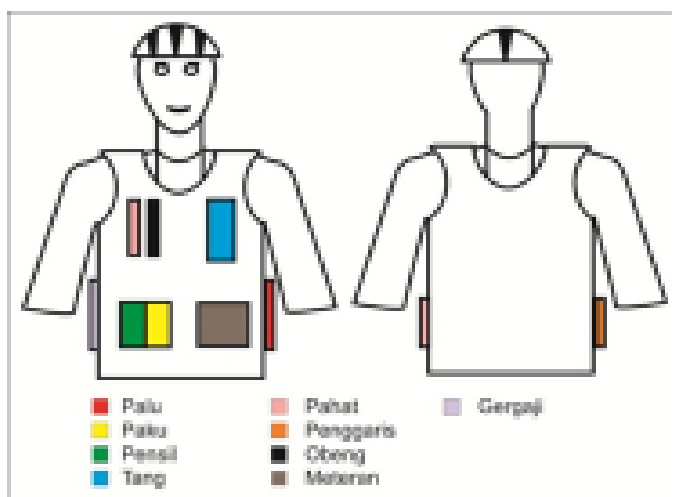

Gambar 1. Konfigurasi penempatan perkakas

Analisis sistem dilakukan guna menentukan sistem apa yang akan dipakai pada Desain Sarana Bawa Pekerja Bangunan di Aktivitas Ketinggian sehingga akan memudahkan dalam aktivitas pengguna ketika akan menggunakan produk ini.

1. Sistem Sambungan Buckle. Side release bucles juga berfungsi sebagai penghubung dan pengunci. Perbedaannya adalah sistem ini memungkinkan tali untuk dipisah dan disatukan kembali. System ini berguna untuk mengikat sarana bawa pada bagian tubuh.

2. Sistem Jahit. Sistem jahitan yang di gunakan yaitu Jahitan lapped, bound, dan jahitan rata yang berfungsi sebagai menjahit

Kantung-kantuk pada rompi sarana bawa dan juga menjahitkan nya pada Wabbing tape.

3. Sistem Zipper. Zipper bias juga di sebut reseleting yang diperlukan untuk menutup pada kantong rompi sarana bawa di bagian tubuh perut pekerja bangunan. Berguna untuk menutup benda-benda kecil agar tidak terjatuh.

Berdasarkan hasil analisa warna yang telah dilakukan, warna dominan yang digunakan untuk produk ini adalah warna Biru. Akan tetapi warna merah juga di ikut sertakan di beberapa bagian Karena warna merah memiliki arti sifat yang kuat dan berani.

Material yang digunakan pada produk Rompi ini adalah cordura karena bahannya yang cukup kuat dan tebal.

Bentuk yang digunakan pada produk sarana bawa ini menggunakan gaya desain modern form follow function yaitu bentuk yang mengikuti fungsi.

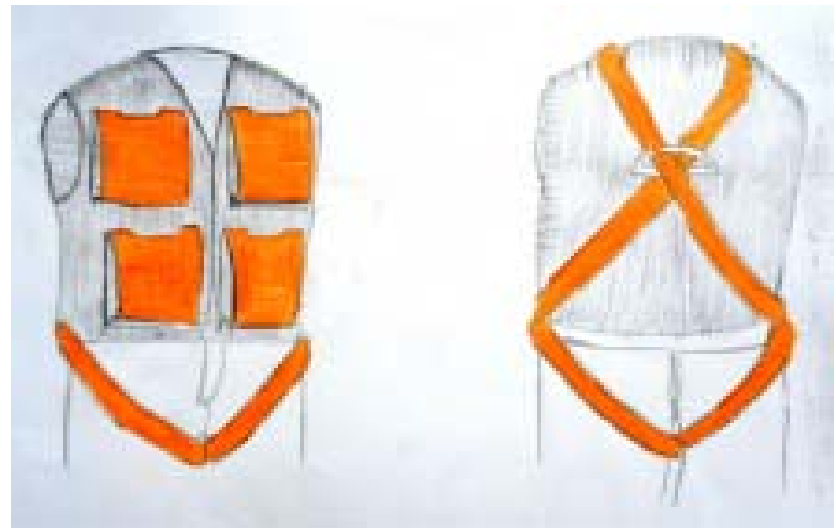

Gambar 2. Alternatif desain terpilih 


\section{Kestif}

Vol. 2, No. 2, April 2015

Berdasarkan analisis beberapa alternatif yang telah dilakukan gambar 2 terpilih untuk perancangan desain rompi pekerja bangunan untuk aktivitas di ketinggian. Selanjutnya alternatif ini dikembangkan lagi beberapa desain untuk mendapatkan hasil yang tepat, salah satunya seperti ditunjukkan dalam gambar 3.
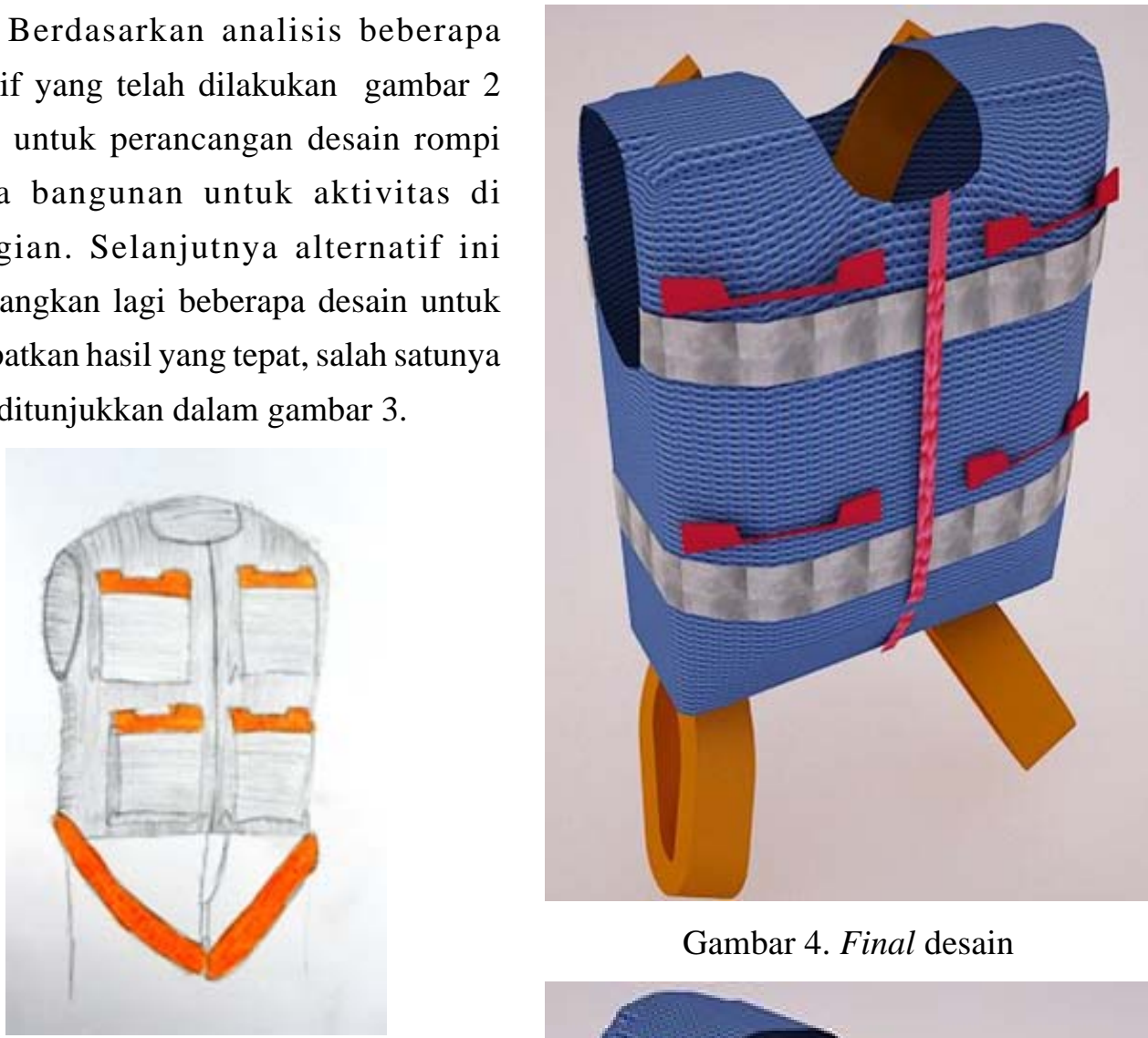

Gambar 4. Final desain

Gambar 3 salah satu Pengembangan alternatif

Berdasarkan analisis beberapa pengembangan desain dari desain terpilih, didapatkan gambar 4 sebagtai dedain final. Desain final ini dijabarkan dengan gambar kerja sehingga bisa diproduksi oleh produsen. Gambar kerja tersebut meliputi gambar isometri, gambar presentasi, gambar tampak, gambar potongan, gambar urai, gambar detail.

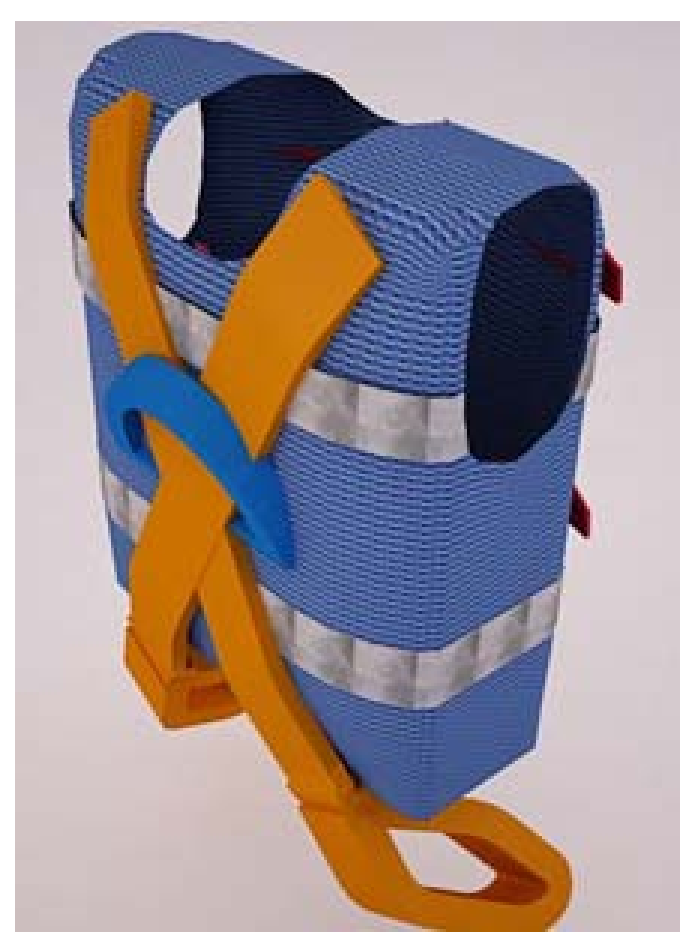

Gambar 5. Final desain 
Royke Vincentius F, Alfianor, Desain Sarana Bawa Pekerja Bangunan Untuk Aktivitas Ketinggian Di Samarinda

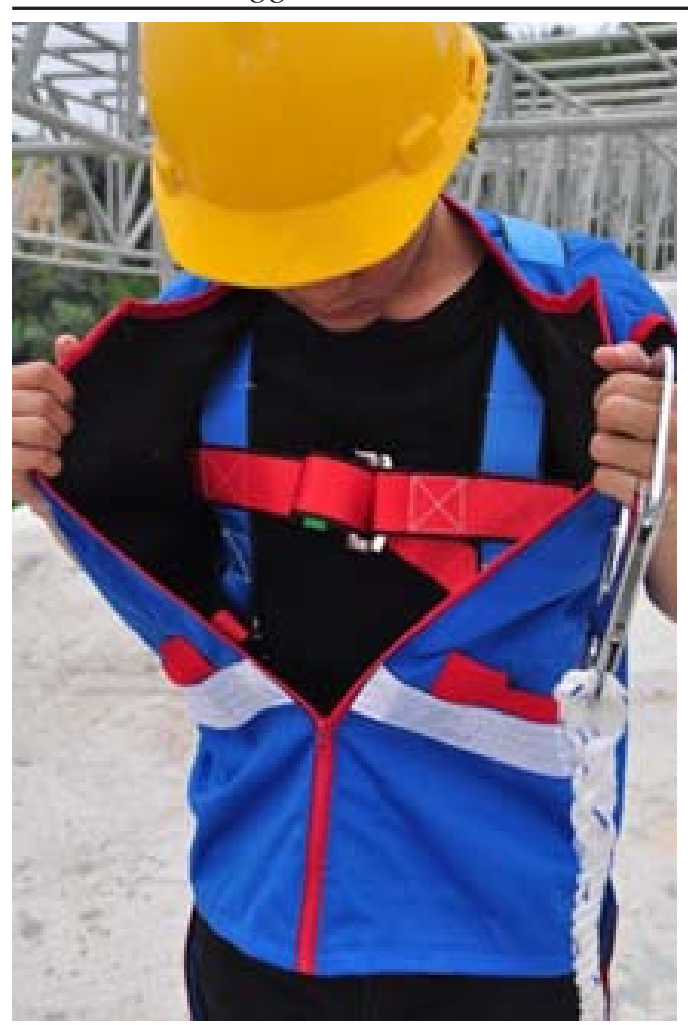

Gambar 6. Operasional produk

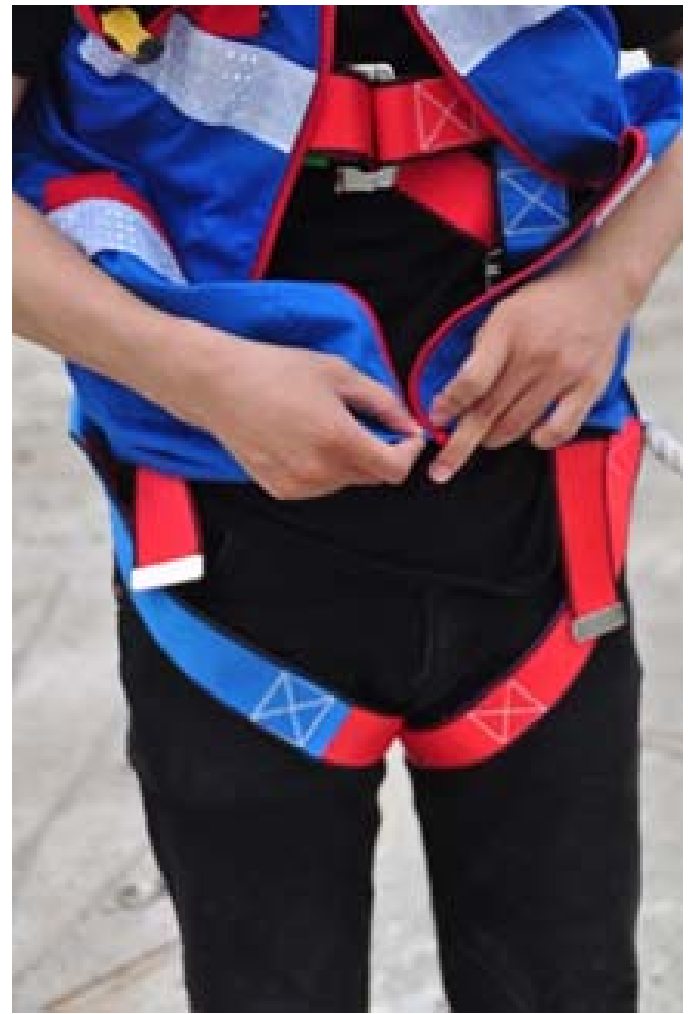

Gambar 7.

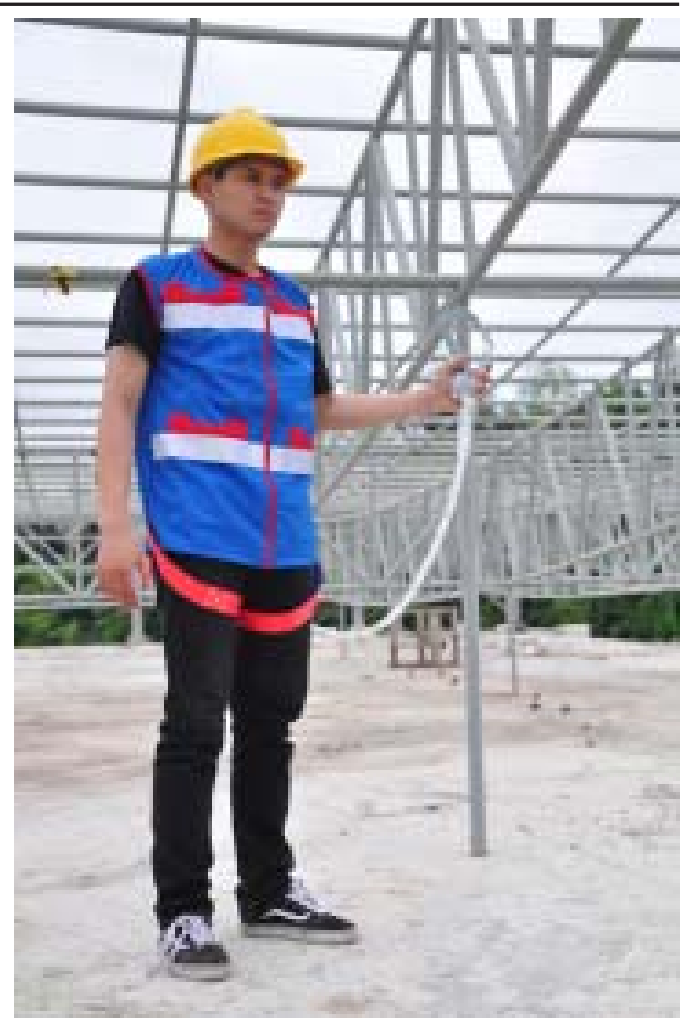

Gambar 8. Operasional produk

\section{Kesimpulan}

Hasil dari perancangan dan pembuatan "Desain Rompi Pekerja Bangunan Untuk Aktivitas Ketinggian Di Samarinda", berupa Rompi yang dikhususkan untuk pekerja bangunan. Ini dirancang sesuai keinginan pengguna baik dari segi fungsi keamanan untuk aktivitas di kondisi ketinggian. Segi estetis berupa inovasi produk yang fungsional dari rompi pada umumnya sebelumnya dengan penambahan fungsi kantung-kantung alat bangunan dan disertai dengan pengaman full body untuk menambah keamanan pekerja di ketinggian.

Untuk di masa mendatang jika produk ini akan diproduksi secara massal, 
perlu diadakan redesign untuk inovasi bentuk dengan tambahan sesuai dengan kekurangan kantong-kantong alat bangunan yang lebih ergonomi serta lebih efisien saat mengambil alat bangunan pada rompi, serta warna yang lebih beragam sesuai keinginan pasar dan ukuran yang disesuaikan dengan tubuh manusia dari yang kecil sampai yang besar. Selain itu, diadakan perbaikan pada sistem kantong untuk di perkuat untuk menahan berat alat bangunan. 
Royke Vincentius F, Alfianor, Desain Sarana Bawa Pekerja Bangunan Untuk Aktivitas Ketinggian Di Samarinda

\section{DAFTAR PUSTAKA}

Cahaya. (2013). Fungsi Dari Full Body Harness. 23 Sebtember 2014. https:// cahayacahya.wordpress.com/2008/09/23/full-body-harness/

Fashion Tips. (2013). Rompi Andalah Sweater Tanpa Lengan. 24 maret 2015. http:/ /rumahoutlet.blogspot.co.id/2009/03/apa-itu-rompi.html

ILO. (2004). Usia Minimum Boleh Untuk Berkerja .

Royan, F.M. (2007). Smart Launching New Product. Jakarta: Penerbit PT Elex Media Komputindo.

Lawson, B. (1990). How Designer Think (2rd ed). The University Press.

Lingga, Gita. (2011, April 26). Hari Keselamatan Kerja Sedunia. International Labaur Organization (ILO) Info Publik. Jakarta. 5 Mei 2016. http://www.ilo.org/jakarta/ info/public/pr/WCMS 155174/lang-en/index.htm.

Mentri Tenaga Kerja dan Transmigrasi. (2014). Data Kecelakaan Kerja DI Indonesia. 9 April 2014. Permenakertrans 180 ttg K3 pada Konstruksi Bangunan

Oscar. (2011). Mengenal Jenis-jenis Kain Drill. 25 Januari 2013. http:// seragamandalas.com/mengenal-jenis-bahan-seragam-drill/

Pramono, E. (2013). Jenis - jenis jahitan pada rompi. 28 Maret, 2015. http:// www.coatsindustrial.com/id/information-hub/apparel-expertise/seam-types

Palgunadi, B. (2008). Desain Produk 3: Mengenal Aspek Disain. Bandung: Penerbit ITB.

Panero, J., \& Zelnik, M. (2003). Dimensi Manusia \& Ruang Interior: Buku Panduan Untuk Standar Pedoman Perancangan. Jakarta: Penerbit Erlangga.

Rianto B. (2014). Tukang Bangunan Adalah Pekerja Yang Mempunyai Ketrampilan Dalam Bidang Membangun Rumah dan Gedung. 9 April 2014.http:// www.riantobangunan.com/2014/04/artitukangbangunan.html

Rianto B. (2014). Data Kecelakaan Kerja DI Indonesia. 9 April 2014. http:// www.riantobangunan.com/2014/04/arti-tukang-bangunan.html 
Royan, F.M. (2007). Smart Launching New Product. Jakarta: Penerbit PT Elex Media Komputindo

Rinaldi Mappuna Mahasiswa S1 Universitas Gunadarma. (1998). Ergonomi dan Anthropometri Tentang Rompi. Universitas Gunadarma.

Taniosutrisno (2014, April 17) Teori Segmentasi Pasar pasar. https:// taniosutrisno.wordpress.com/2014/10/07/segmentasi-pasar-analisis-demografi/

Wedzig, E. (2013). System Zipper pada rompi. 9 April 2015 http://www.wadezig.com/ membedakan-zipper-dari-jenisnya/ 